\title{
MODELING STUDY OF PV POWER PLANTS IN DIFFERENT IRAQ'S GOVERNORATES
}

\author{
Abdulmunem R. Abdulmunem Mohammed Hassan Jabal, Muhannad Zedan Khlefia \\ abdulmunemraad@yahoo.com, mhjutm@gmail.com, Bearing2018design@gmail.com \\ Electromechanical Engineering Department, University of Technology / Baghdad. Iraq
}

\section{ABSTRACT}

The available huge amount of solar radiation in Iraq all over the year can be regarded as a useful energy source. It can be utilized to generate electrical energy using PV panel's power plants. Therefore, it is important to recognize the behavior of these PV Panels through the year with changing in amount of the solar radiation and weather temperature. The monthly average (daily and hourly) of extraterrestrial, global, diffused, and beam radiation, with PV panel's temperature and electrical efficiency of different tilt angle is studied in three Iraqi's cities. The results indicated that the total radiation ranges are greater in Karbala than Samarra and Basra cities; despite of the extraterrestrial radiation in Basra higher value than Samarra and Karbala cities. The higher magnitude in the monthly average solar radiation in any city is not necessarily best location for construction PV power plant, because the electrical performance of PV panels is affected by its temperature. Rising in temperature led to drop in the PV panel's efficiency.

KEYWORDS: Simulation Program; PV Power Plants; Total Radiation;

$$
\begin{aligned}
& \text { دراسة نموذجية لمحطات الطاقة الكهروضوئية في مختلف محافظات العراق } \\
& \text { عبدالمنعم رعد عبدالمنعم محمد حسان جبل مهند زيدان خليفة } \\
& \text { الجامعة التكنولوجية / قعم الهندسة الكهروميكانيكية / بغدادـ العراق فيدان }
\end{aligned}
$$

يمكن اعتبار الكمية الهائلة من الإشعاع الثمسي في العراق على مدار العام مصدراً مفيداً للطاقة ؛ من المككن

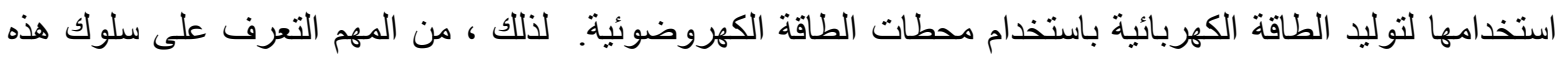

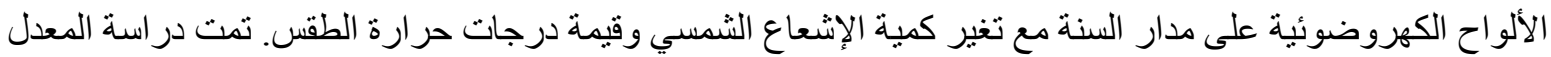

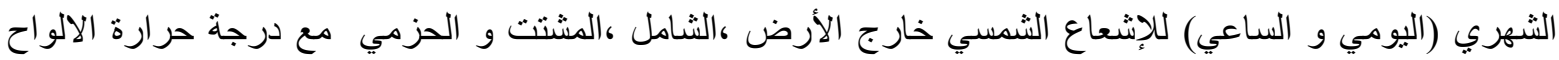

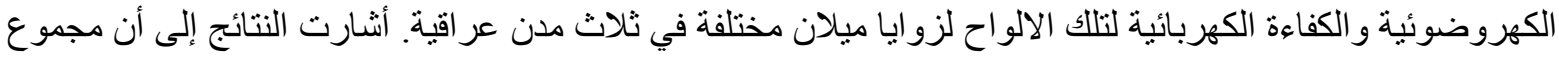

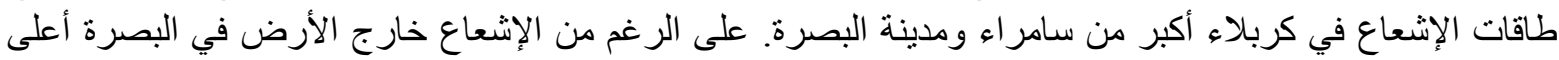

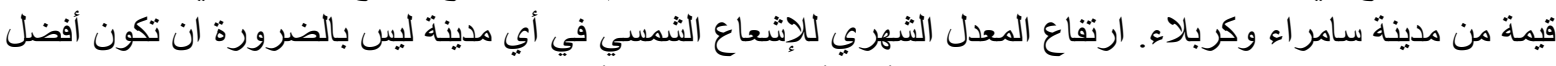

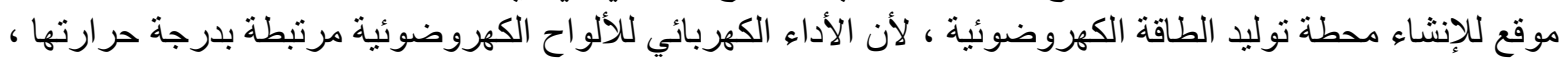

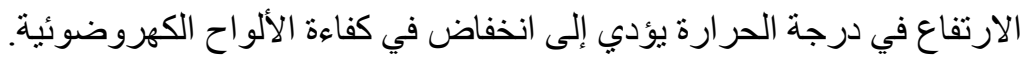




\section{Nomenclature:}

$\mathrm{a}^{\prime}, \mathrm{b}^{\prime}=$ Regression constants

$\bar{H}=$ Monthly average daily solar radiation $\left[\mathrm{J} / \mathrm{m}^{2}\right.$-day $]$

$\bar{I}=$ Monthly average hourly solar radiation $\left[\mathrm{J} / \mathrm{m}^{2}-\mathrm{h}\right]$

$\mathrm{I}=$ Curent $(\mathrm{A})$

$\mathrm{KT}=$ Clearance index

$\mathrm{N}=$ Day length $[\mathrm{hr}]$

$\mathrm{ND}=$ Number of days at each month (17 Jan, 16 Feb, 16 Mar, 15 Apr, 15 May, 11 Jun, 17 Jul, 16 Aug, 15 Sep, 15 Oct, 14 Nov and $10 \mathrm{Dec}$ )

$\mathrm{n}=$ Bright sunshine hours $[\mathrm{hr}]$

$\mathrm{V}=$ Voltage $(\mathrm{V})$

$\mathrm{P}=$ Power $(\mathrm{W})$

$\mathrm{T}=$ Temperature (deg.C)

$\bar{\eta}=$ Monthly average daily efficiency $(\%)$

$\beta=$ Tilt angle

$\gamma=$ Azimuth angle

$\delta=$ declination Angle (deg)

$\theta=$ Incidence angle $(\mathrm{deg})$

$p=$ the ground reflection coefficient (for ordinary grass or concrete $=0.2$, and for snow-covered ground $=0.6$ )

$\varphi=$ Latitude angle (deg)

$\omega=$ hour angle $(\mathrm{deg})$

$\Gamma=$ Temperature coefficient of silicon cell (0.0045).

\section{Subscripts:}

$\mathrm{b}=$ Beam

d= Diffuse

$\mathrm{e}=$ electrical

$\mathrm{g}=$ global

$\max =$ Maximun

mpp $=$ Maximun power point

$\mathrm{o}=$ Extraterrestrial

$\mathrm{PV}=$ Photovoltaic

$\mathrm{n}=$ Nominal

$\mathrm{r}=$ reflected

$\mathrm{st}=$ sunrise on a tilted surface

$\mathrm{s}=$ sunrise on a horizontal surface

$\mathrm{T}=$ Total

\section{INTRODUCTION}

The energy demand will become five times larger than what it is now by current trend in progress technology and continues in innovation. Thus it is obvious that the present conventional energy resources will be not able to meet the increasing in the demand of energy. The higher consumption rate in the resources of conventional energy is the other responsible important factor on the crisis of energy. Renewable energy is the best solution for the energy demand.

The photovoltaic systems are one form of solar (Renewable) energy application in this field. Its performance for generating electrical power depends on irradiance intensity falling and photovoltaic panel temperature. The rising in the temperature led to drooping in the generated power at the same irradiance intensity H. Hussien et al. [2015, 2017].

Iraq's location makes it one of important countries to construct photovoltaic system power plant, by utilizing the large amount of the falling solar radiation along the year. The design and prediction of the solar energy device at a certain location demands the global solar radiation on a horizontal surface M. Hussain, et al. [1999].

There are different models proposed to estimate global solar radiation. The relationships between the number of sunshine hours and monthly mean clearness index in Romania was studied by Badescu[1999], the correlation between the measurements of global solar radiation and the mean daily of meteorological (temperature, humidity, pressure at sea level, pressure of vapour and sunshine hours) was obtained in Egypt at different parts are study by Trabea and Shaltout[2000]. The hourly global solar radiation forecast using artificial intelligence techniques was studied by Sfetsos and Coonick [2000]. A global solar radiation models was 
reviewed and tested to compute the monthly average daily global radiation on a horizontal surface using data on Turkey, Konya by Menges et al. [2006]. Monthly averaged data for thirty years of various meteorological parameters was used to estimate the monthly averaged solar radiations (global, diffuse and direct solar radiation) on horizontal surface and tilted surface over 10 districts in Bangladesh by M. A. Islam et al. [2016]. The solar photovoltaic module temperature is one of the most important factors responsible for lowering the performance of photovoltaic modules is predicted by Mondol, J.D. et al. [2005]. C. H. Cox, et al. [1985], gave a computer simulation of flat-plate PV/T collectors in order to determine the PV panel efficiency and interaction depending on the temperature of PV panel.

This work aimed to estimate the daily, hourly and monthly average of global, diffuse, beam and total radiation falling on horizontal and different tilt angles, and to simulate photovoltaic panel's temperature to predict the photovoltaic panel's performance at any constructed PV power plant. A simulation program is constructed and investigated experimentally, depending on the meteorological conditions of some selected Iraqi cities (Samarra, Karbala and Basra) along the year by using MATLAB.

\section{METHODOLOGY}

\section{Direction of beam radiation}

The angle of declination $(\delta)$ can be expressed as Khan [2010]:

$$
\begin{aligned}
& \delta=23.45 * \sin \left[\frac{360}{370}(N D-80)\right] \\
& \omega=15^{*}[\text { solar time }-12] \\
& \omega_{\mathrm{s}}=\cos ^{-1}[-\tan (\varphi) \tan (\delta)] \\
& \mathrm{N}=2 \omega_{\mathrm{s}} / 15 \\
& \tan \left(\gamma_{s}\right)=\frac{\sin (\oplus)}{\sin (\varphi) * \cos (\oplus)-\cos (\varphi) * \tan (\delta)}
\end{aligned}
$$

And the incidence angle:

$$
\begin{aligned}
\cos (\theta)= & {[\sin (\delta) \sin (\varphi) \cos (\beta)]-[\sin (\delta) \cos (\varphi) \sin (\beta) \cos (\gamma)]+[\cos (\delta) \cos (\varphi) \cos (\beta) \cos (\omega)]+} \\
& {[\cos (\delta) \sin (\varphi) \sin (\beta) \cos (\gamma) \cos (\omega)]+[\cos (\delta) \sin (\beta) \sin (\gamma) \sin (\omega)] }
\end{aligned}
$$

For horizontal surface,

$$
\cos (\theta)=\cos (\delta) \cos (\varphi) \cos (\omega)+\sin (\delta) \sin (\varphi)
$$

\section{Estimation of Monthly Averaged Solar Radiation (daily, hourly)}

\section{Monthly average daily solar radiation (global, diffuse and beam)}

The used equations for estimating the monthly average, daily solar radiation on different surfaces are expressed by Khan [2010] as:

\section{a- For horizontal PV panel surface}


The monthly average, daily extraterrestrial radiation $\left(\bar{H}_{o}\right)$ is:

$\bar{H}_{o}=\frac{86400}{\pi} * 1367 *\left[1+0.033 \cos \left(\frac{360 N D}{365}\right)\right]+\cos \varphi \cos \delta \sin \omega_{s}+\omega_{s} * \sin \varphi \sin \delta$

And, the monthly average, daily global radiation $\left(\overline{H_{g}}\right)$ is:

$\frac{H_{g}}{H_{0}}=a^{\prime}+b^{s}\left(\frac{\bar{n}}{N}\right)$

Where: $a^{d}=0.25$ and $b^{d}=0.5$ are applicable at anywhere in the world.

The monthly average, daily diffused radiation $\left(\overline{H_{d}}\right)$ is :

$\frac{H_{\bar{d}}}{\overline{H_{g}}}=1.354-1.570 * \overline{K T} \quad$ where: $0.3 \leq \overline{K T} \leq 0.7$

Where $\left(\overline{K T}=\frac{H_{g}}{H_{o}}\right)$ known as monthly average daily clearness index.

Then, the monthly average, daily beam radiation $\left(\bar{H}_{b}\right)$ can be found using:

$\bar{H}_{b}=\bar{H}_{g}-\bar{H}_{d}$

b- For inclined PV panel surface

The monthly average, daily total radiation $\left(\overline{H_{T}}\right)$ can be found using:

$\frac{H_{T}}{H_{g}}=\left(1-\frac{H_{d}}{H_{g}}\right) \overline{R_{b}}+\frac{H_{d}}{H_{g}} \overline{R_{d}}+\overline{R_{r}}$

Where, $\overline{R_{b}}, \overline{R_{d}}$ and $\overline{R_{r}}$ are the brief symbols for equations and can be represented as:

For surface facing to south $\gamma=0$

$\overline{R_{b}}=\frac{\omega_{s t} \sin (\delta) \sin (\varphi-\beta)+\cos (\delta) \sin \left(\omega_{g t}\right) \cos (\varphi-\beta)}{\omega_{g} \sin (\delta) \sin (\varphi)+\cos (\delta) \sin \left(\omega_{g}\right) \cos (\varphi)}$

$\overline{R_{d}}=\frac{1+\cos (\beta)}{2}$

$\overline{R_{r}}=\rho\left[\frac{1-\cos (\beta)}{2}\right]$

\section{Monthly average hourly solar radiation (global, diffuse and beam)}

The used equations for estimating the monthly average, hourly solar radiation on different surfaces are expressed by Khan [2010] as:

\section{a- For horizontal PV panel surface}

The monthly average, hourly extraterrestrial radiation $\left(\overline{I_{o}}\right)$ is:

$\bar{I}_{\circ}=3600 * 1367 *\left[1+0.034 \cos \left(\frac{360 * \mathrm{ND}}{365.25}\right)\right] * \cos (\theta)$ 
And, the monthly average, hourly global radiation $\left(\overline{I_{g}}\right)$ is:

$\frac{T_{g}}{H_{g}}=(a+b \cos \omega) \frac{T_{0}}{H_{0}}$

Where:

$a=0.409+0.5016 \sin \left(\omega_{s}-60\right)$

And

$b=0.6609+0.4767 \sin \left(\omega_{s}-60\right)$

The monthly average, hourly diffused radiation $\left(\overline{I_{d}}\right)$ is:

$\frac{T_{\bar{d}}}{H_{\bar{d}}}=(\bar{a}+\bar{b} \cos \omega) \frac{T_{0}}{H_{0}}$

Where:

$\bar{a}=0.4992+\left[\frac{0.27}{\overline{H_{\bar{d}}} / H_{g}}\right]$ for $\frac{\overline{H_{d}}}{H_{g}} \leq 0.7$

$\bar{a}=0.76+\left[\frac{0.113}{H_{\bar{d}} / H_{g}}\right]$ for $0.7 \leq \frac{H_{d}}{H_{g}} \leq 0.9$

And

$\bar{b}=\frac{(1-\bar{a})\left(\sin \omega_{g}-\omega_{g} \cos \oplus_{g}\right)}{\oplus_{g}-0.5 \sin \left(2 \oplus_{g}\right)}$

The monthly average, hourly beam radiation $\left(\bar{I}_{b}\right)$ can be found using:

$\bar{I}_{b}=\bar{I}_{g}-\bar{I}_{d}$

\section{b- For inclined PV panel surface}

The monthly average, hourly total radiation $\left(\overline{I_{T}}\right)$ can be found using:

$\frac{T_{T}}{T_{g}}=\left(1-\frac{\overline{T_{d}}}{\bar{T}_{g}}\right) \overline{r_{b}}+\frac{\overline{T_{d}}}{T_{g}} \overline{r_{d}}+\overline{r_{r}}$

Where, $\overline{r_{b}}, \overline{r_{d}}$ and $\overline{r_{r}}$ are the brief symbols for equations and $\overline{R_{b}}, \overline{R_{d}}$ and $\overline{R_{r}}$ respectively, as represented in equations (13), (14) and (15):

\section{Estimation of PV Panel Temperature and Efficiency}

The PV panel temperature affects its performance. The temperature of these panels can be estimated by using correlation, Mondol, J.D. et al. [2005]

$\overline{T_{P V}}=\left(30+\left(0.0175 *\left(\overline{H_{T}}-300\right)\right)+\left(1.14 *\left(\overline{T_{a u r}}-25\right)\right)\right)$

Based on the panel temperature, its electrical efficiency can be calculated from equation $\mathbf{C}$. $\mathbf{H}$. Cox, et al. [1985]. 
$\overline{\eta_{e}}=\eta_{n}\left[1-\Gamma\left(\overline{T_{P V}}-T_{n}\right)\right]$

\section{PV panels Electrical performance}

Generally, the generated power from the PV panels can be found from the measured data using: C. H. Cox, et al. [1985]

$\mathrm{P}_{\max }=\mathrm{I}_{\mathrm{mpp}} * \mathrm{~V}_{\mathrm{mpp}}$

While, the electrical efficiency of PV panels $\left(\eta_{e}\right)$ is :-

$\overline{\eta_{e}}=\frac{\mathrm{P}_{\max }}{\mathrm{G} * \mathrm{~A}_{\mathrm{PV}}}$

\section{SIMULATION PROGRAM}

The constructed simulation program is done using MATLAB with input meteorological conditions for the selected Iraqi governorates. The input data for solution program with a matrix that consist of 12 rows for the months number and 10 columns for different tilt angles from $\left(0^{\circ}\right)$ to $\left(90^{\circ}\right)$, to get a simulation data at each month at any tilt angle. Figure (1) shows locations (Longitudes, latitudes) of the selected cities with constructed program flowchart.

\section{EXPERIMENTAL PART}

To investigate the conducted data from the simulation program, two $\left(1.125 \mathrm{~m}^{2}\right) \mathrm{PV}$ panels with $(100 \mathrm{Watt})$ at standard conditions (i.e. at Irradiation $=1000 \mathrm{~W} / \mathrm{m}^{2}$, Temperature $=25$ ${ }^{\circ} \mathrm{C}$ ) connected in parallel are used for this propose. The PV panel's base frame is faced to south ability to incline with different angles. To get the average PV panel temperature, two K-type thermocouples with accuracy $( \pm 0.4 \%)$ are used in top and bottom PV panel surface. Solar Irradiation is measured with an (LI-COR PY 82186) pyranometer with accuracy $( \pm 0.2 \%)$. A (DT80) data logger is used to record the temperature and irradiance data with interval's (1 hour). Maximum power point tracer (MPPT) with accuracy $( \pm 0.5 \%)$ is used in order to maximize the power output of the panels under different irradiation. The tests are done in alBasra city $\left(30.5^{\circ} \mathrm{N}\right.$, latitude) at $\left(15^{\text {th }}\right.$ April, $16^{\text {th }}$ August and $10^{\text {th }}$ December $\left./ 2017\right)$. The system configuration are showed in figure (2).

\section{RESULTS AND DISCUSSION}

In this study, to simulate the real conditions for the selected three studied cities (Samarra, Karbala and Basra), the constructed simulation needs a daily monthly average of sunshine hours and air temperature as input information for any studying city. The recorded data obtained from the Iraqi's meteorological station during (2017), as presented in figure (3).

In figures (4 and 5), as using programmed equations (8) and (9) in the constructed program to estimating the monthly average hourly and daily of the extraterrestrial radiation values, that can't be measured for the selected cities in this study(Samarra, Karbala and Basra).It is obvious that the extraterrestrial radiation values for the selected cities (Samarra, Karbala and Basra) have a same behavior along the year, but in general form Basra city has higher magnitude in the hourly and daily monthly average of extraterrestrial solar radiation 
than Karbala and samara respectively, this is due to its nearest location to equator (latitude location) than other cities.

From figure (6) the simulated results of the beam and diffused daily monthly average radiation are presented. It is seen that Karbala city has highest magnitude of beam radiation than other cities, while Basra city is the highest in the diffused radiation values along the year. In the results, Karbala city has highest values in global radiation, as presented in figure (7). It is the same behaviors for the estimated results from the simulation program for the hourly monthly average of beam, diffused and global radiation at (12:00 PM) as presented in figures (8 and 9).

In AL-Basra city (30.5o N, latitude) at (15th April, 16th August and 10th December / 2017) respectively, the simulation program validation presented in figures (10), (11) and (12) by giving a comparison between experimental results and simulated program results for the total radiation falling on the used PV panels surface that inclined in (30o) and temperatures and electrical efficiency of PV panels. As shown, there are very close agreement between experimental results and simulated program results at 15th April when the weather was almost clearly, while at 16th August and 10th December, there are some difference between experimental results and simulated program results, this due to the dusts and clouds that are difficult to predict caused. In general, it can dependence on the constructed program give a clear idea and helpful for estimating the PV panel's performance at any location for construction PV Power plant.

The collected of monthly average daily total solar radiation with different PV panel's tilt angles in Samarra, Karbala and Basra cities are presented in figures (13), (14) and (15) respectively. From these results, its can seen that there are optimum tilt angle for best collected radiation in each month as the changes in the direction of beam radiation angles that listed in equations $(1-7)$, but for fixed PV system along the year, the $\left(30^{\circ}\right)$ tilt angle gives the best annual collected radiation from PV panels, it must be noted that the fixed PV panels system must be directed toward to south, because Iraq lies in the northern hemispherical Khan [2010]. From figure (16), it seen that Karbala city gets best collected radiation along the year at this fixed angle $\left(30^{\circ}\right)$ as shows.

The silicon materials that used in PV cells manufacturing are very affected on temperature i.e. (rising in temperature of silicon cells gives drooping in power production) Abdulmunem [2017], then rising in the monthly average solar radiation with months produces rising in the monthly average weather temperature, that leads to decrease in PV panels efficiency with months especially in summer season despite of highest in radiation magnitude as shown in figure (17). The monthly average total daily temperature with electrical efficiency of PV panels inclined at $(30 \mathrm{deg})$ is presented in this figure. It can seen that the PV panel temperatures have higher value in Basra than Karbala and Samarra respectively, Also Samarra city have lowest magnitude in temperature at the same month that leads to better PV panels performance than Karbala and Basra respectively.

The used of constructed program in this work is very helpful for providing immediate and accurate values for the solar radiation behavior and PV system temperature with efficiency for any location in Iraq. The obtained result gives a clear idea of the monthly average (hourly and daily) solar radiation and PV panels temperature and efficiency behavior along the year.

\section{CONCLUSIONS}

It is very important to utilize the solar radiation that falls on Iraq during the year to generate electrical energy by constructing a photovoltaic power plant. From this study it can be conclude the following: 
1-The higher magnitude in the monthly average solar radiation in any city not necessarily best location for construction power plant, because the electrical performance of PV panel is related to its temperature. Rising in temperature leads to dropping in the PV panels efficiency (Basra city have higher magnitude in the monthly average solar radiation hourly and daily of extraterrestrial radiation but Samarra give best electrical performance).

2-For each month there is best tilt angle for best of PV panel's performance, but for the south facing fixed system along the year a tilt angle about $\left(30^{\circ}\right)$ gives best annual collected radiation.

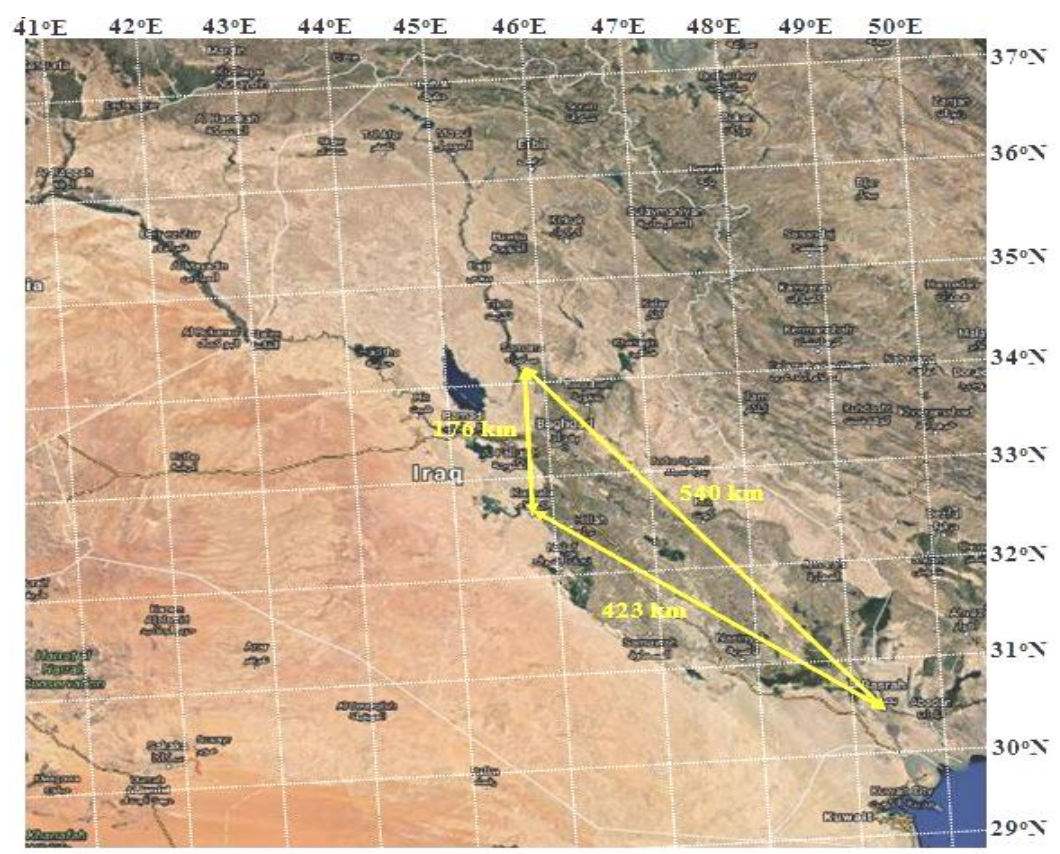

(a) 


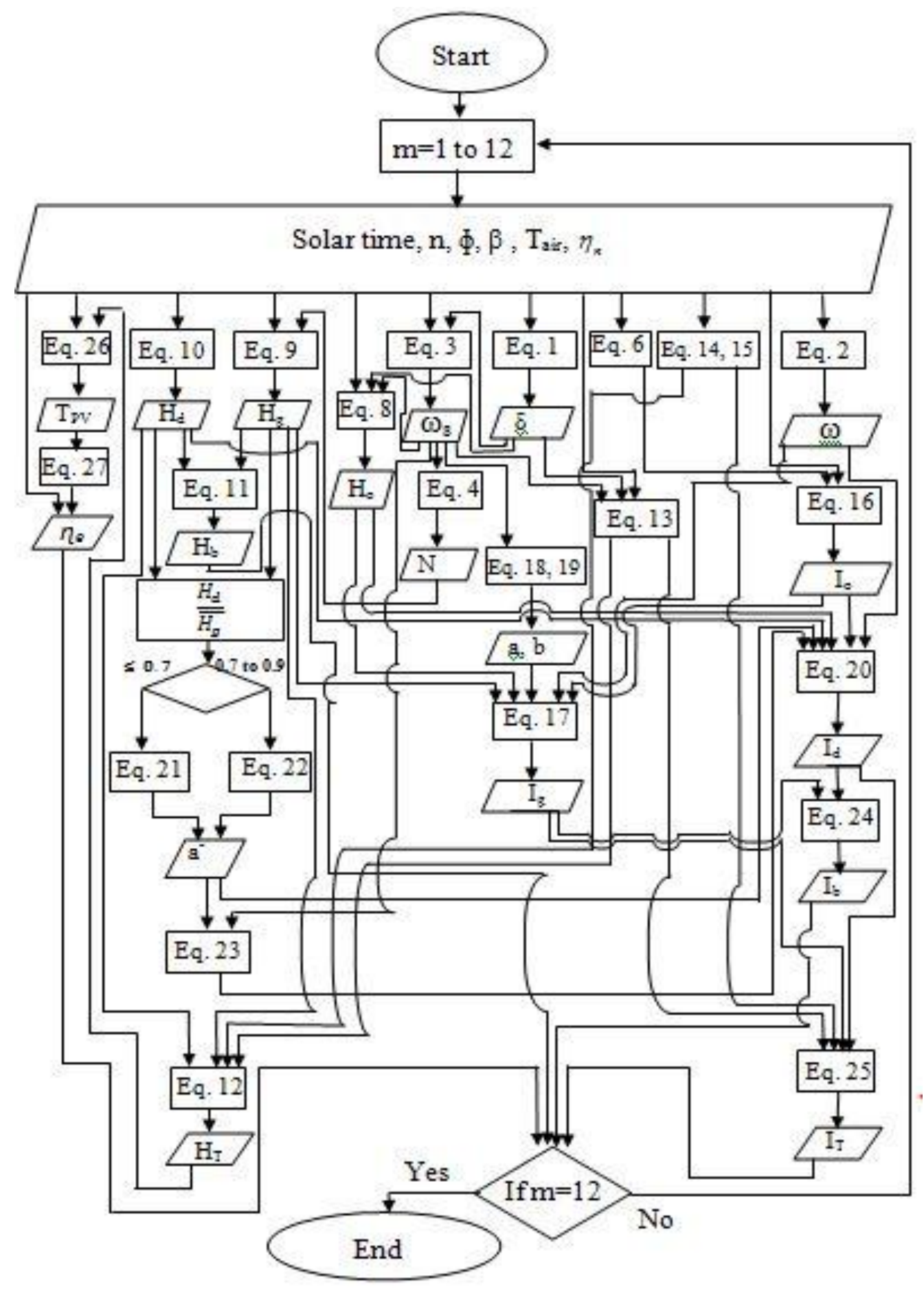

(b)

Fig. 1, (a) studied cities satellite photo, (b) constructed program flowchart. 


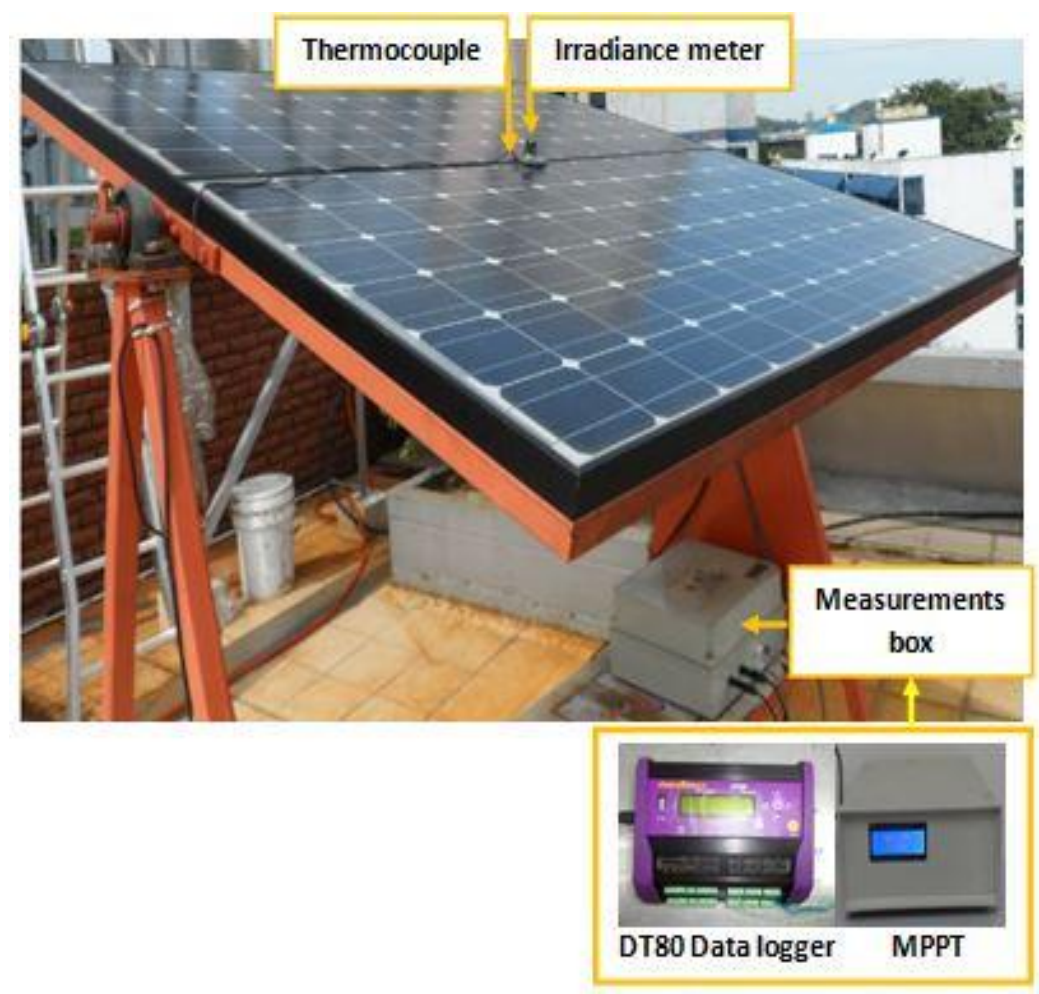

Fig.2, system configuration.

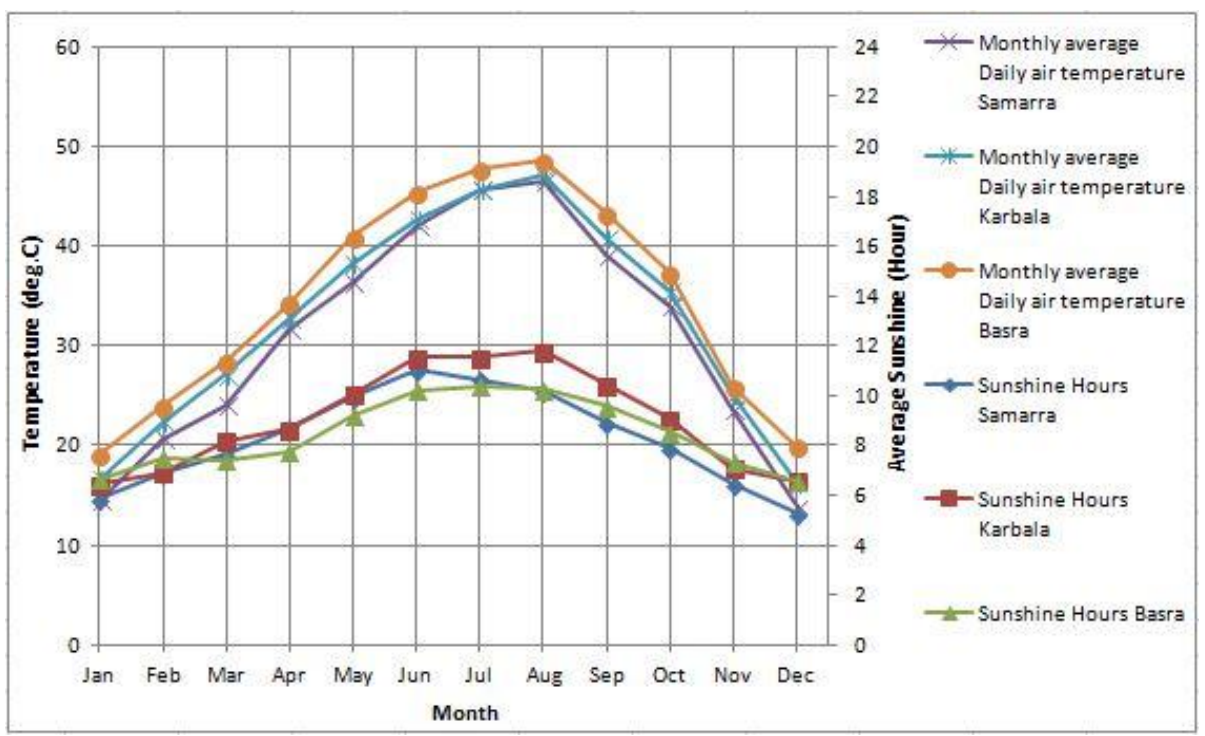

Fig. 3, monthly average, daily sunshine hour with air temperature. 


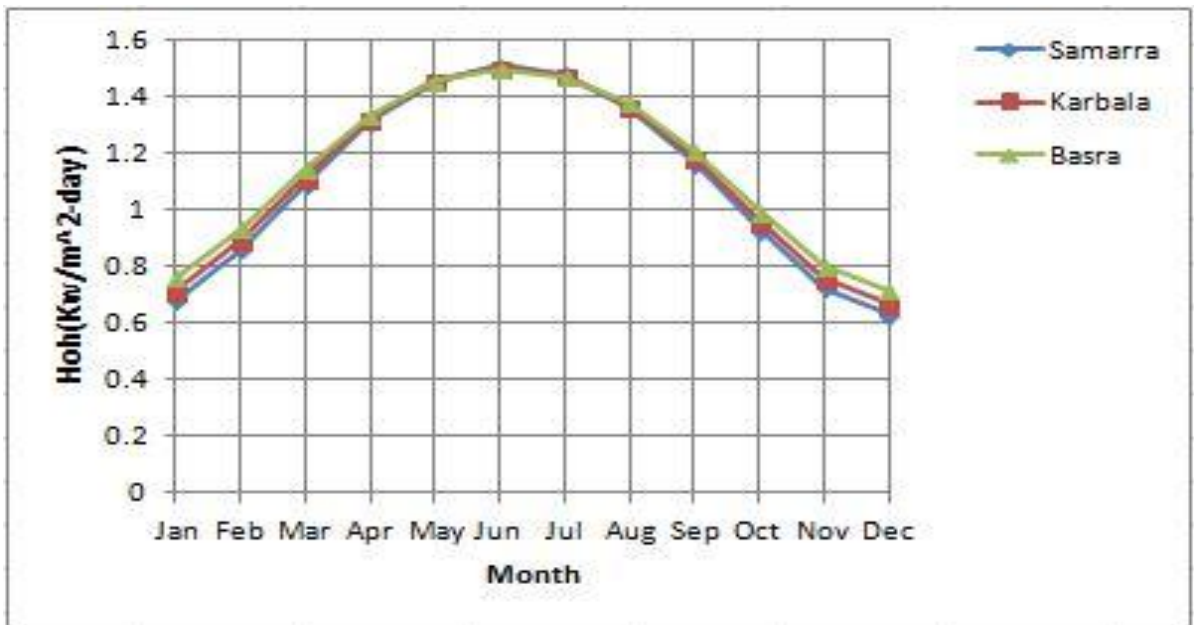

Fig. 4, monthly average, daily extraterrestrial radiation.

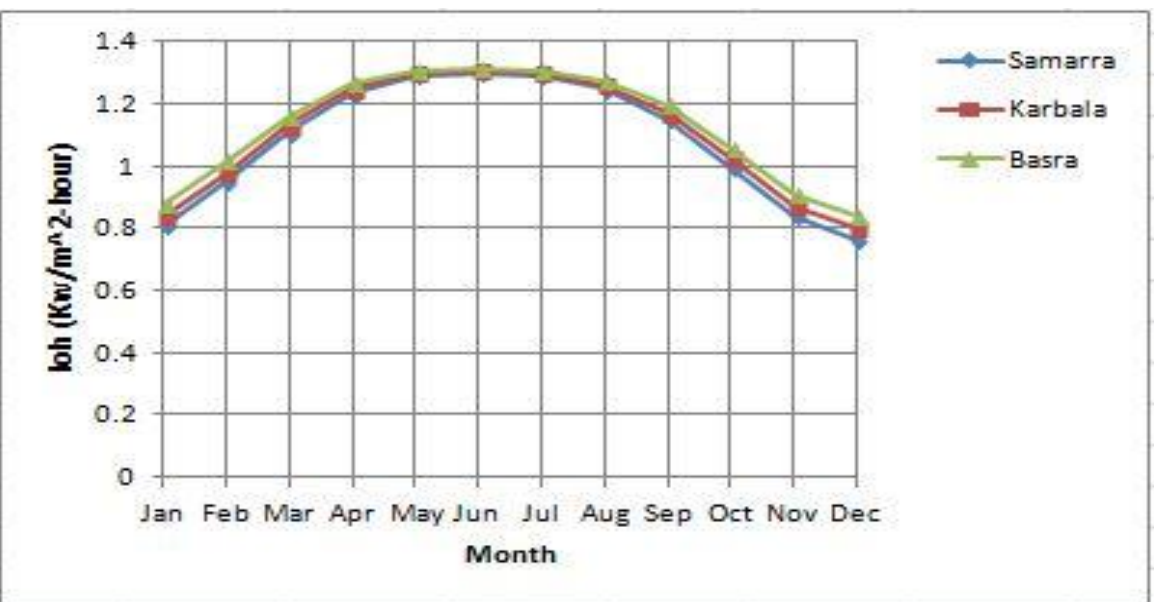

Fig. 5, monthly average, hourly extraterrestrial radiation at (12:00 PM).

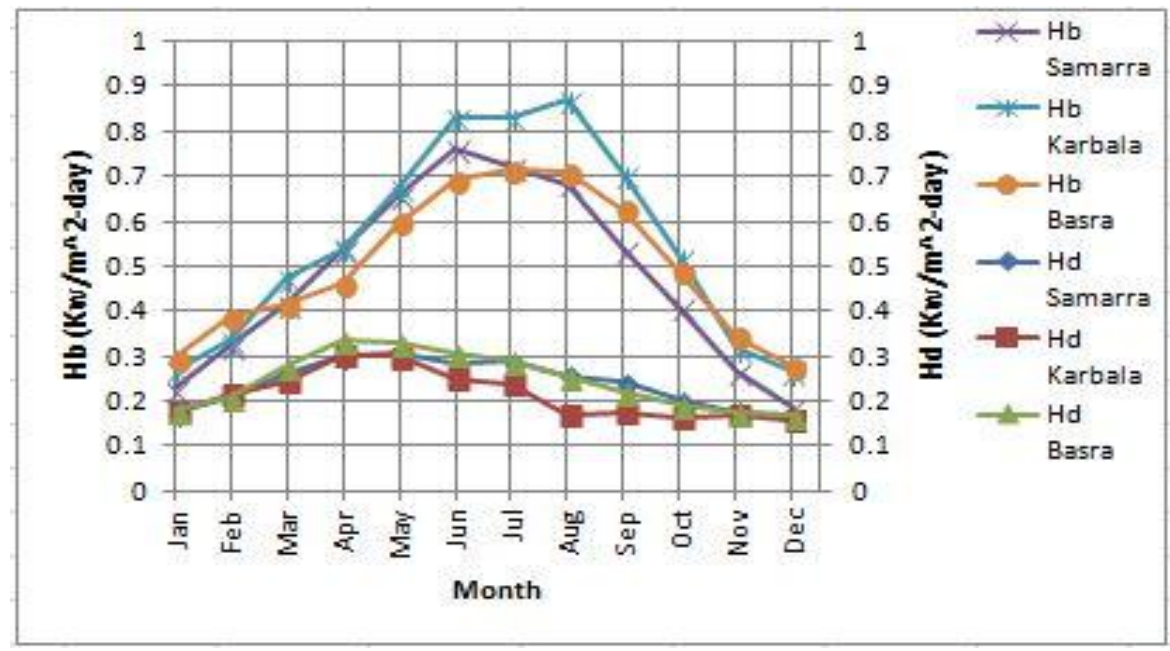

Fig. 6, monthly average, daily beam and diffused radiation. 


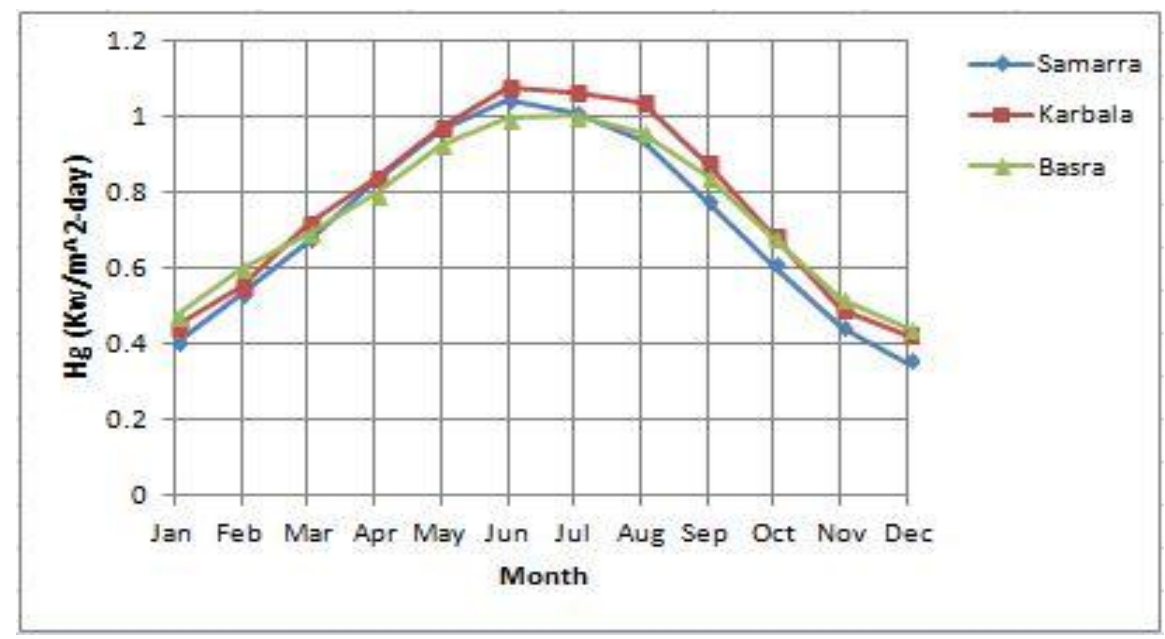

Fig. 7, monthly average, daily global radiation.

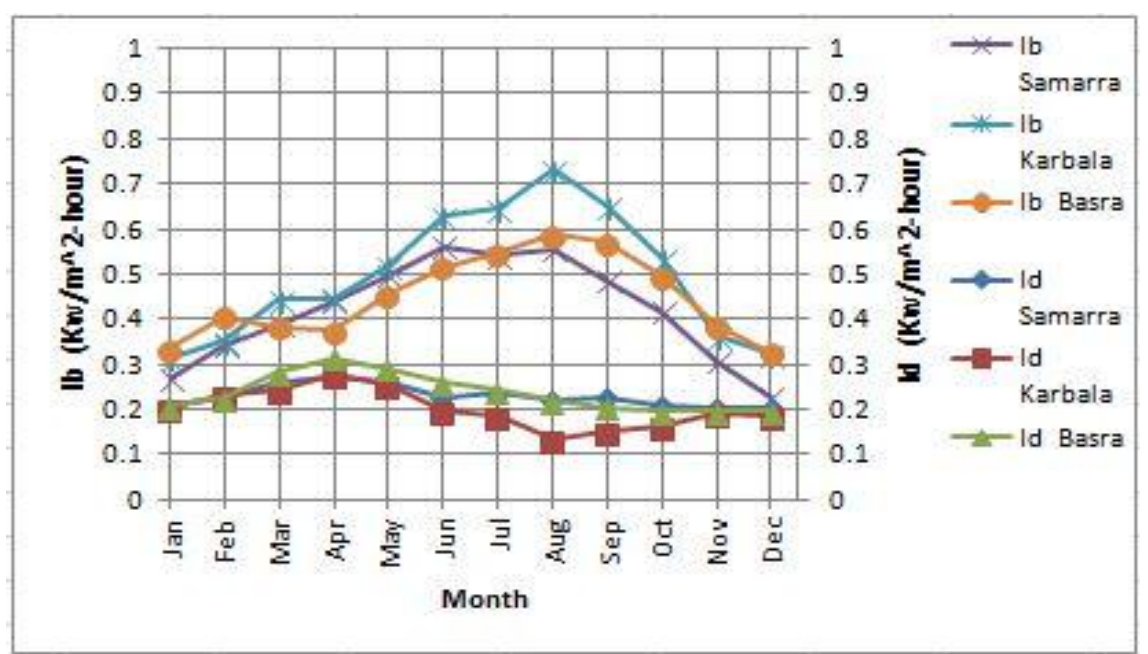

Fig. 8, monthly average, hourly beam and diffused radiation at (12:00 PM).

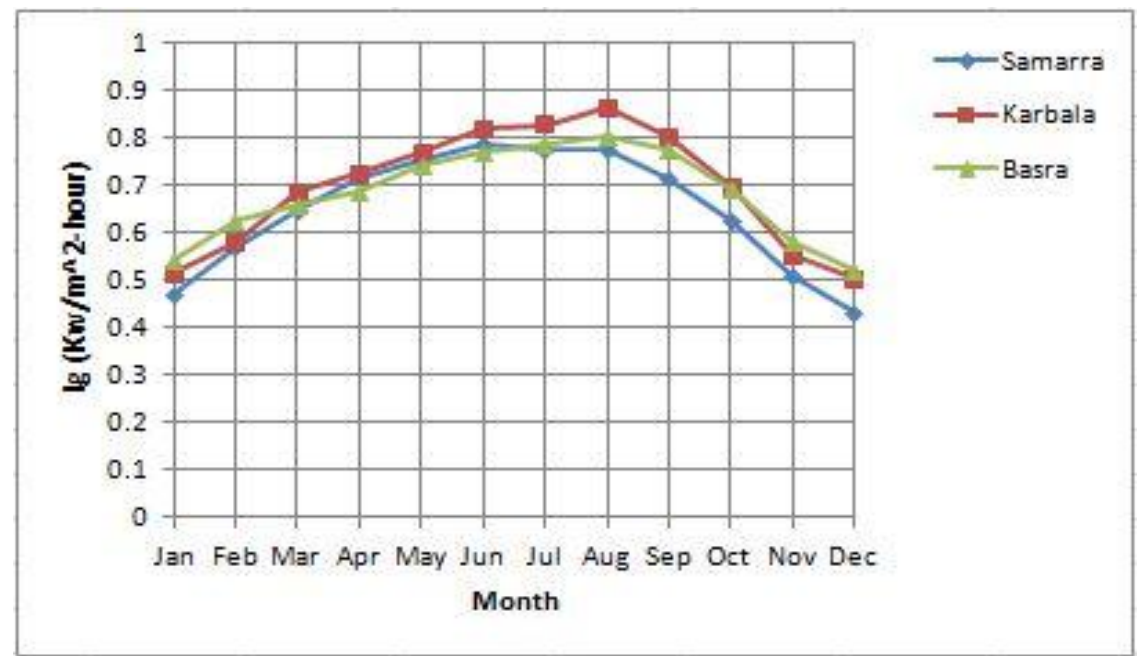

Fig. 9, monthly average, hourly global radiation at (12:00 PM). 


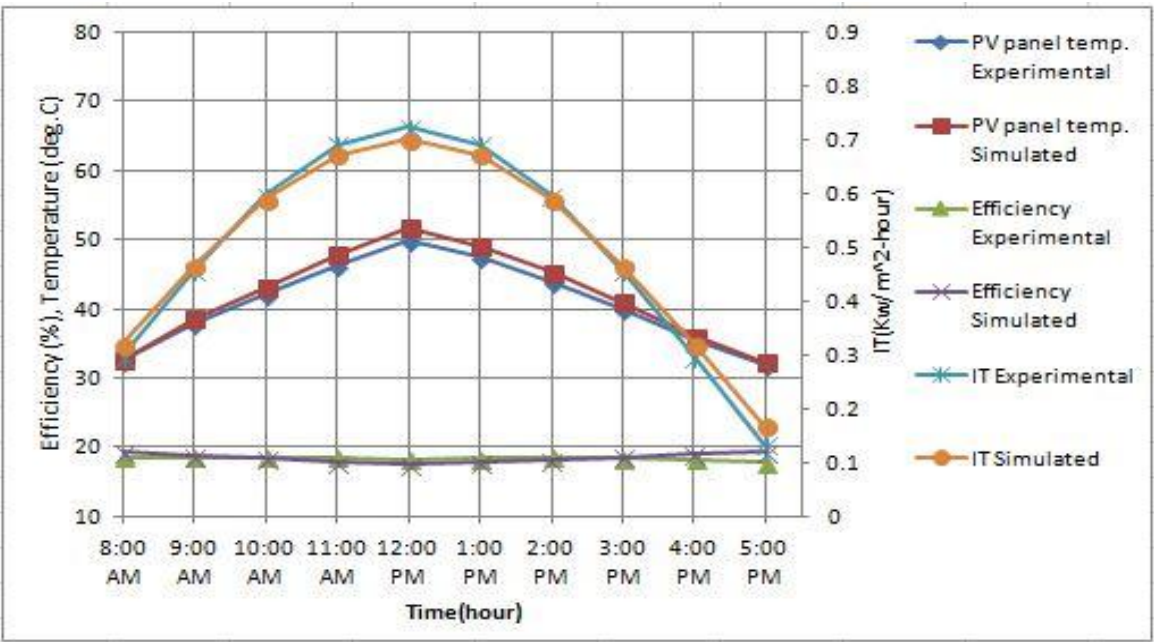

Fig. 10, Comparison of the simulated program results at $\left(15^{\text {th }}\right.$ April/2017) in Basra city.

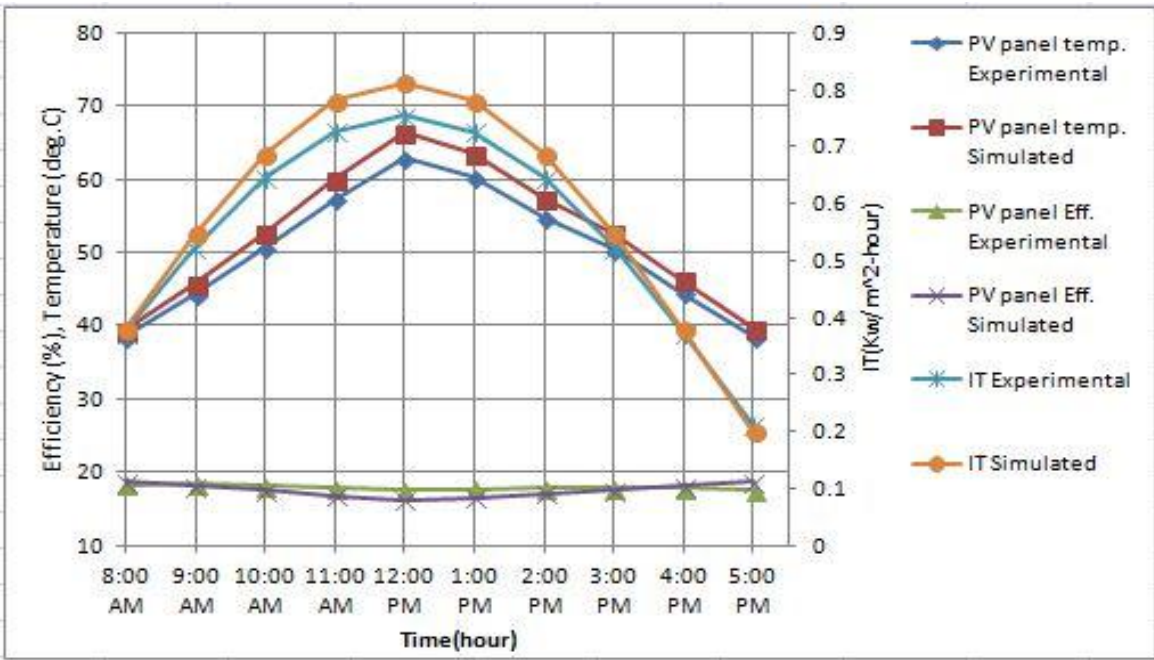

Fig. 11, Comparison of the simulated program results at $\left(16^{\text {th }}\right.$ August $\left./ 2017\right)$ in Basra city.

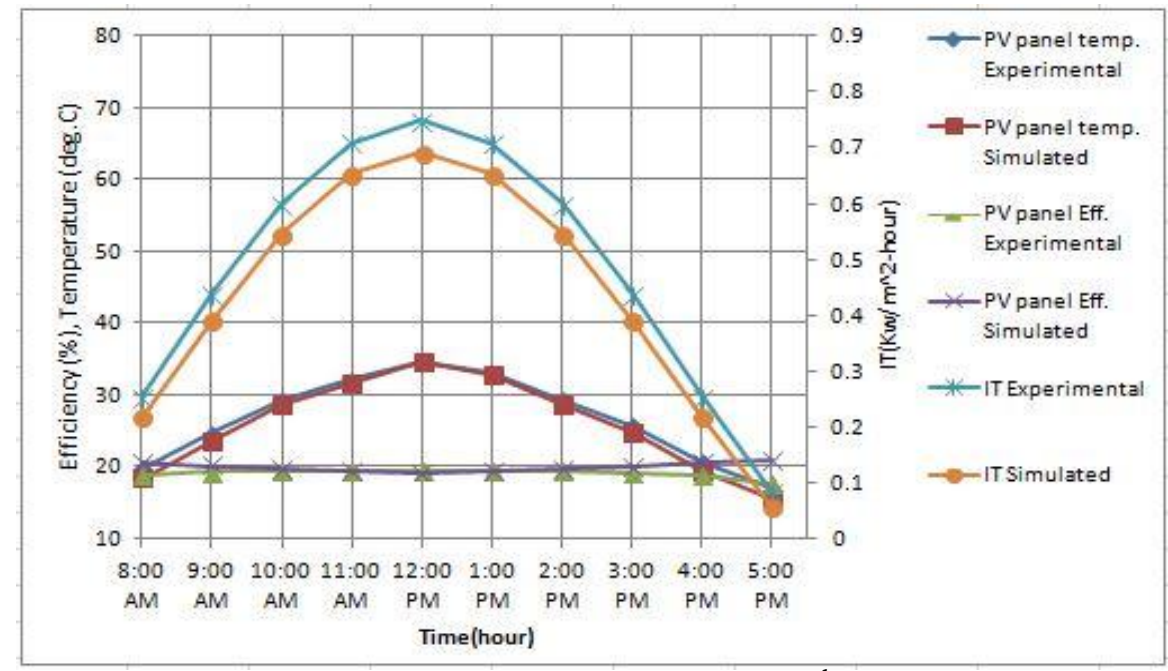

Fig. 12, Comparison of the simulated program results at $\left(10^{\text {th }}\right.$ December $\left./ 2017\right)$ in Basra city. 


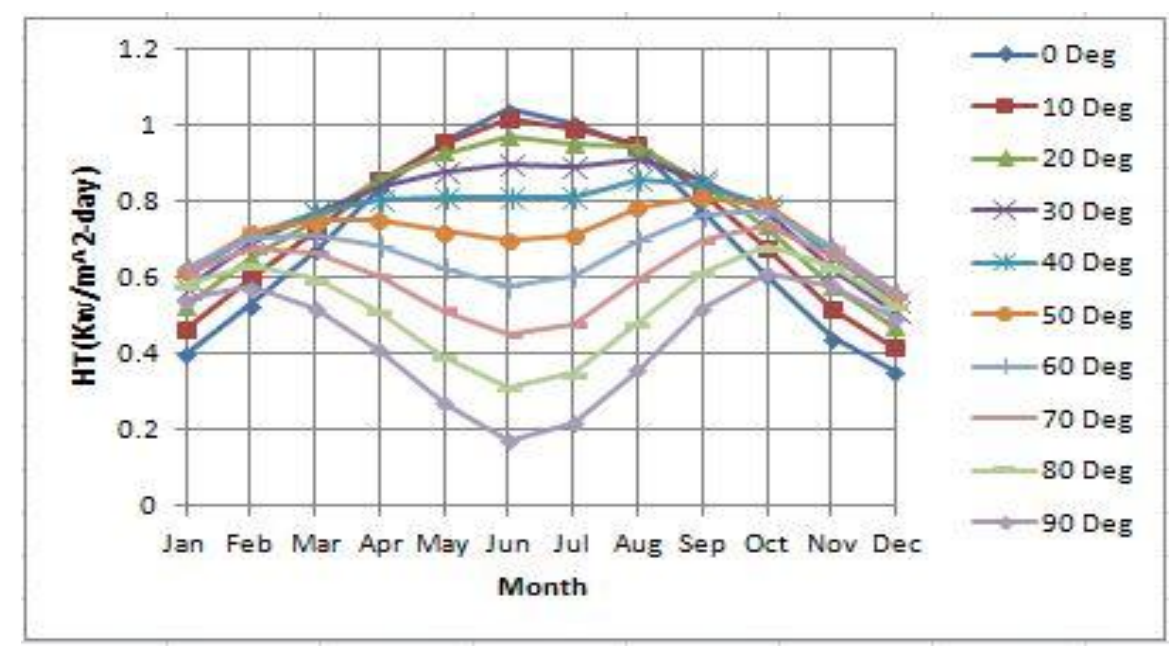

Fig. 13, monthly average, total daily radiation on inclined PV panels surface in Samarra city.

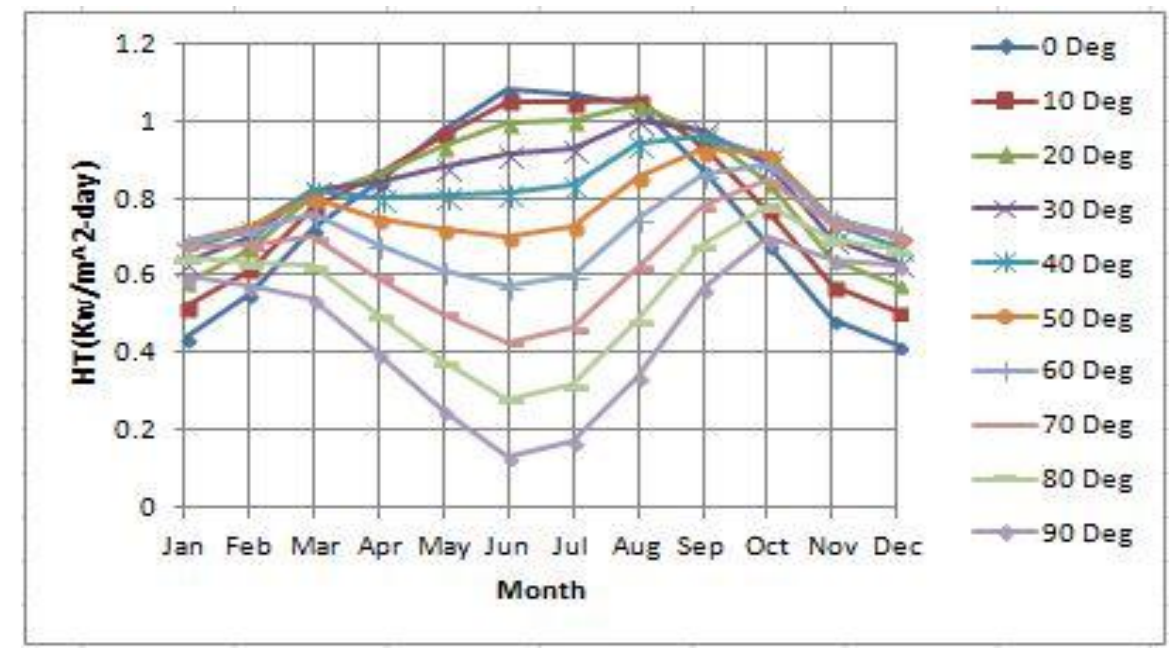

Fig. 14, monthly average, total daily radiation on inclined PV panels surface in Karbala city.

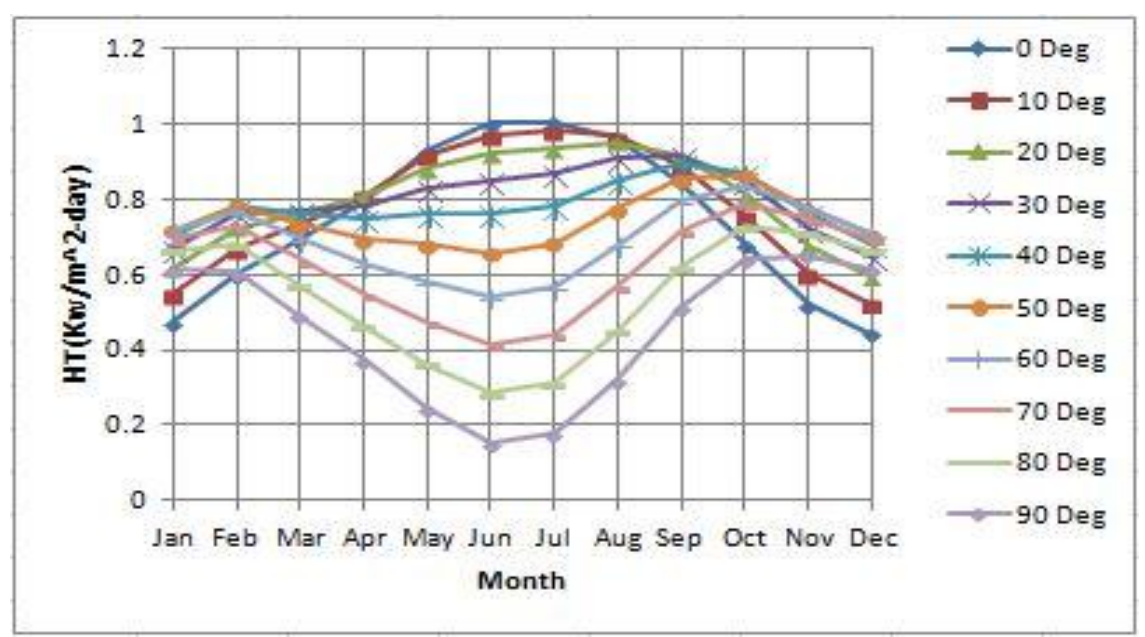

Fig. 15, monthly average, total daily radiation on inclined PV panels surface in Basra city. 


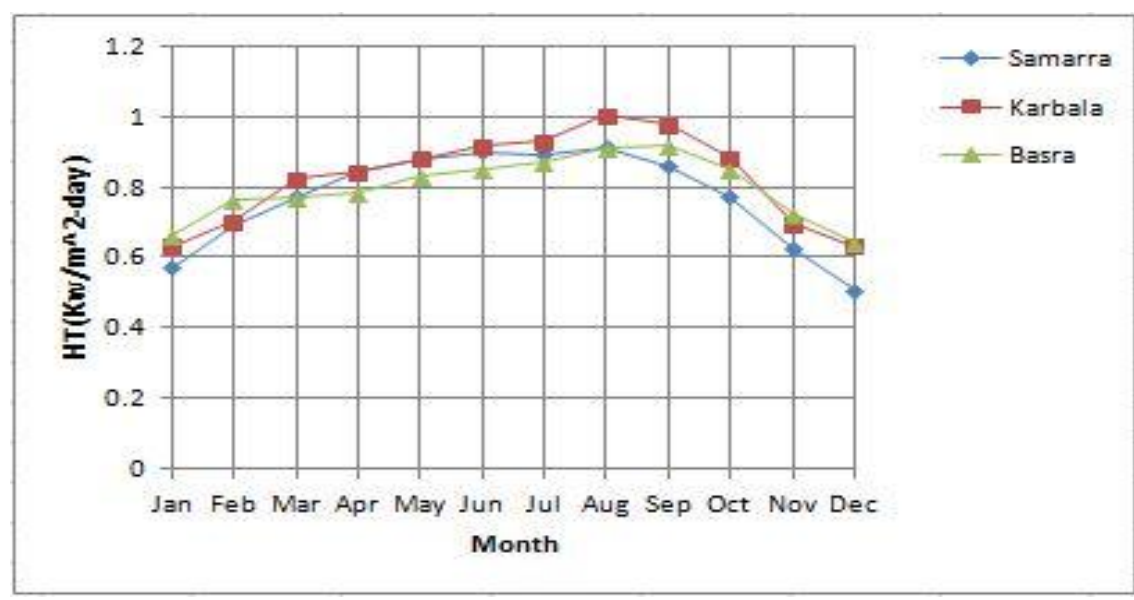

Fig. 16, monthly average, total daily radiation for PV panels inclined at (30 deg).

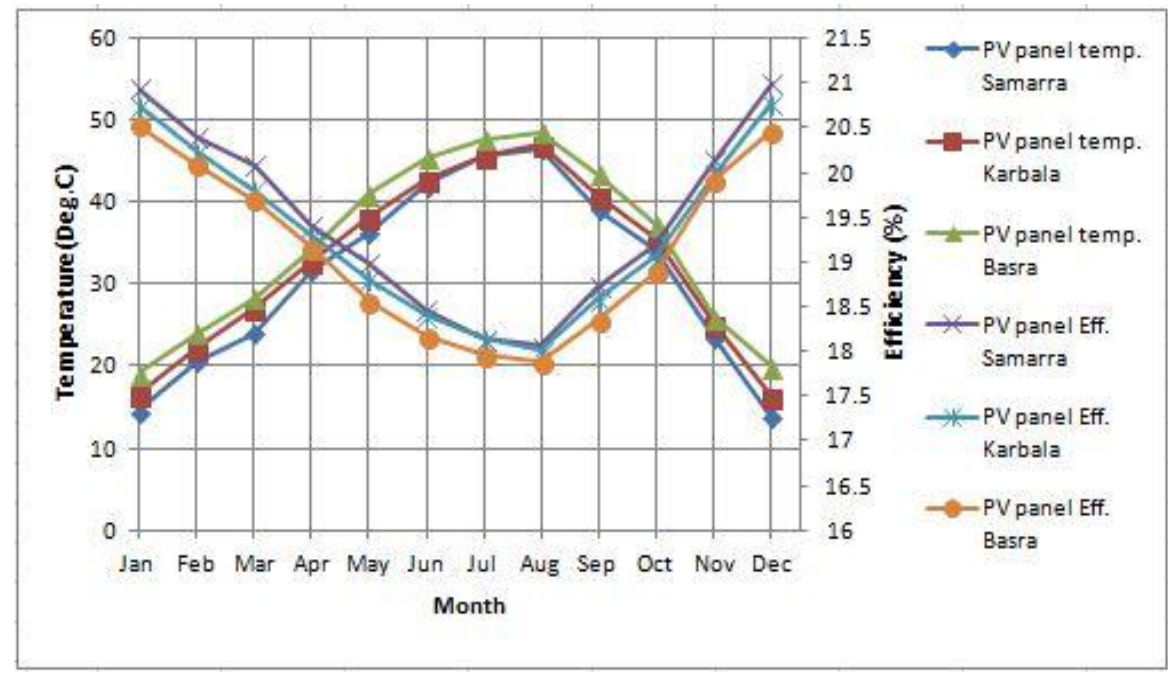

Fig. 17, monthly average, total daily temperature with electrical efficiency of PV panels inclined at (30 deg).

\section{REFERENCES}

A. A. Trabea, and M. A. Shaltout, Correlation of global solar-radiation with meteorological parameters over Egypt. Renew. Energy Journal, 21 ( 2000 ), 297-308.

A.Sfetsos, and A. H. Coonick, Univariate and multivariate forecasting of hourly solar radiation with artificial intelligence techniques. Solar Energy Journal, 68 (2000), 169- 178. 
Abdulmunem R. Abdulmunem, "PASSIVE COOLING BY UTILIZING THE COMBINED PCM / ALUMINUM FOAM MATRIX TO IMPROVE SOLAR PANELS PERFORMANCE: INDOOR INVESTIGATION", The Iraqi Journal For Mechanical And Material Engineering, Vol.17, No4, Dec. 2017.

B. H. Khan;"Non-Conventional Energy Resources", Book, Second Edition; McGraw Hill, 2010.

C. H. Cox, III and P.RAGHURAMAN, DESIGN CONSIDERATIONS FOR FLATPLATEPHOTOVOLTAIC/ THERMAL COLLECTORS, Solar Energy Journal Vol. 35, No. 3, pp. 227-241, 1985

H. A. Hussien, A. H. Noman and A. R. Abdulmunem, "Indoor Investigation for Improving the Hybrid Photovoltaic /Thermal System Performance Using Nanofluid (AL2O3-Water)." Engineering \& Technology Journal 33(Part (A), No.4): 889-901, 2015.

H. A. Hussien, A. H. Noman and A. R. Abdulmunem, "An Experimental Investigation on the Performance Enhancement of Photovoltaic/Thermal Panel Using a Tracking System and Nanofluid (Al 2O3)," Engineering and Technology Journal, Vol. 35, Part A, No.5,pp. 493-508, 2017.

H. O. Menges, C. Ertekin and M. H. Sonmete, Evaluation of global solar radiation models for Konya, Turkey. Energy Conversion Management Journal, 47 (2006), 3149-3173.

Hashim A. Hussien, Ali H. Noman and Abdulmunem R. Abdulmunem, (2015). Improving of the photovoltaic/thermal system performance using water cooling technique. IOP Conference Series: Materials Science and Engineering, IOP Publishing.

Hussien, H. A., M. Hasanuzzaman, Abdulmunem, R. Abdulmunem. (2014). Enhance photovoltaic/thermal system performance by using nanofluid. Clean Energy and Technology (CEAT) 2014, 3rd IET International Conference on, IEEE.

M. Hussain, L. Rahman, and M. M. Rahman, Techniquse to obtain improved prediction of global radiationfrom sunshine duration Renewable Energy Journal, 18 (1999), pp. 263-275.

Mohammad Ashraful Islam, Md. Saiful Alam, Komol Kanta Sharker, Sanjoy Kumar Nandi, Estimation of Solar Radiation on Horizontal and Tilted Surface over Bangladesh, Computational Water, Energy, and Environmental Engineering Journal, 2016, 5, 54-69.

Mondol, J.D., Y.G Yohanis, M. Smyth and B. Norton, 2005. Long-term validated simulation of a building integrated photovoltaic system. Solar Energy Journal, 78: 163-176.

V. Badescu, Correlations to estimate monthly mean daily solar global irradiation: Application to Romania. Energy Journal, 24 ( 1999), 883-893. 